\title{
Die kerkregtelike posisie van die kind in die Neder- duitsch Hervormde Kerk van Afrika, met besondere verwysing na lidmaatskap, doop, nagmaal en tug
}

\author{
W A Dreyer \\ Universiteit van Pretoria
}

\begin{abstract}
The position of the child in the Nederduitsch Hervormde Kerk van Afrika with specific reference to membership, baptism, eucharist and discipline

The position of the child in the church has been taken for granted for many years. This article gives a historical perspective on the church orders of Calvin, Bucer, the Netherlands and the Nederduitsch Hervormde Kerk van Afrika, and analizes those articles that shed any light on the position of the child in the church. Matters such as children's membership of the church, infant baptism, children's communion and discipline are discussed from the viewpoint of church order.
\end{abstract}

\section{INLEIDEND}

Wanneer die publikasies vanuit die Nederduitsch Hervormđe Kerk van Afrika (NHKA) nagegaan word, is dit opmerklik dat daar nog baie min aandag aan die kerkregtelike posisie van die kind gegee is. Blaai 'n mens deur die 50 jaargange van die Hervormde Teologiese Studies, vind jy artikels oor doop, verbond, uitverkiesing, kategese en onderwys - maar hierdie artikels het net met die kind in ' $n$ afgeleide sin te make, sover die kind van belang is binne ' $n$ bepaalde leerstuk of binne ' $n$ bepaalde kerklike praktyk. Die kind is egter geen kerklike dogma of te reduseer tot 'n kerklike praktyk nie (Dreyer 1985:1). Aan die kind assodanig en sy plek in die kerk word min aandag gegee. Eers in 1991 tydens die Predikantevergadering van die NHKA is daar bespreking gevoer oor die kind in die kerk, aan die hand van twee referate, te wete 'n Nuwe-Testamentiese perspektief op die kind van prof A G van Aarde en Kinders in die erediens van prof $\mathrm{MJ}$ du $\mathrm{P}$ Beukes.

Hieruit kan afgelei word dat die kind of nie belangrik is nie, of dat die plek van die kind so vanselfsprekend is dat daar geen moeite gedoen word om dit te omskryf nie. Die eersgenoemde moontlikheid lyk tog nie korrek nie, aangesien daar in die kerklike praktyk besondere aandag aan die kind gegee word in die kategese en die jeugwerk. Mens kry eerder die indruk dat die kerklike praktyk van honderde jare 'n sekere vanselfsprekendheid ten opsigte van die kind in die kerk teweeggebring het - 
die kind is maar daar en die kerk gaan soos altyd voort. Enkele faktore het egter die situasie ingrypend laat verander, en die kerk kan die kind nie meer vanselfsprekend en kritiekloos aanvaar nie. Enkele faktore is die volgende:

- Sekularisasie is besig om nie net volwassenes se geloof te ondergrawe nie, maar ook die geloof van kinders. Daarom sal die kerk in sy teologiese arbeid krities moet rekenskap gee hoe hy God ver-taal aan die kind in die moderne wêreld. Dit is die hermeneutiese problematiek, waarmee die kerk in elke faset van sy verkondiging aan die kind rekening moet hou. Ten opsigte van die hermeneutiese problematiek het verskillende teoloë al waardevolle bydraes gelewer.

- Daar is voortdurende kritiek vanuit die pinkstergroepe teen die kerk se praktyk om kinders te doop. Die kerk het teologies reeds die kinderdoop afdoende gefundeer, maar kerkregtelik is daar 'n mate van spraakverwarring, ook in die huidige kerkwet van die NHKA. Die kerk sal heider en duidelik sy standpunte ten opsigte van die kind, lidmaatskap, doop, nagmaal, tug en ander verwante sake moet formuleer en dit ook laat gestalte vind in die nuwe kerkorde wat tans opgestel word. Dit sal ook die apologetiese en polemiese arbeid van die kerk vergemaklik.

- Die kerk het te make met gesinsverbrokkeling, gebrek aan huisgodsdiens en gelowige opvoeding deur ouers. So word die kind uitgelewer aan ongeloof en kerklike verwildering. Dit word dus uiters noodsaaklik dat die kerk doelgerig en effektief die evangelie aan die kind sal verkondig.

'n Kerkwet of kerkorde gee 'n bepaalde struktuur aan die wyse waarop die kerk die evangelie an die kind verkondig. Daarom moet die kerkorde gestruktureerd en teologies verantwoord ook aan die kind se posisie in die kerk aandag gee. Hierdie studie gee nie aandag aan die kerk se verkondiging aan die kind as sodanig nie, maar wil die kerkregtelike posisie van die kind probeer ophelder. Daar word aan die kind se lidmaatskap, sy doop, nagmaalgebruik asook opsig en tug aandag gegee.

\section{IIDMAATSKAP}

\subsection{Die kerkwet van die NHKA}

Lidmaatskap van die NHKA word kerkordelik gereël in artikel 3 van die kerkwet. Artikel 3 stel dat persone lidmaat van die kerk is wat: (a) In die gemeenskap van die kerk opgeneem is deur die doop; (b) Deur belydenis van geloof lidmaat geword het van die kerk; (c) Kinders van lidmate van die kerk is (Kerkwet NHKA 1989:1).

Ons merk dus in hierdie artikel 'n drieledige onderskeiding in lidmaatskap op: gedoopte lidmate, belydende lidmate en lidmate wat nie gedoop is of belydenis van geloof afgelê het nie maar opgrond van hul geboorte uit gelowige ouers gereken word as lidmate van die kerk. Die teologiese agtergrond van die derde is die 
genadeverbond, wat God se genade nie individualisties aan enkelinge verbind nie, maar met die gelowige gesin werk as basiese bousteen van God se verbond met die mens. Die versweë veronderstelling is dat hierdie derde kategorie lidmate klein kindertjies sal wees, omdat ouers volgens die kerkwet onder die verpligting staan om hulle babas ten doop te hou. Solank as wat die babas nog nie gedoop is nie, is hulle reeds op grond van hul ouers se geloof lidmate van die kerk. Met hierdie bepaling is daar alreeds probleme in 'n situasie waar almeer mense nie hulle kinders ten doop hou nie as gevolg van onverskilligheid. Teoreties kan dit beteken dat iemand wat al volwasse is en nog nooit gedoop of belydenis van geloof afgelê het nie, lidmaat van die kerk bly bloot op grond van die feit dat sy ouers lidmaat van die kerk is. Myns insiens sal daar 'n duideliker omskrywing van hierdie derde kategorie gegee moet word, aangesien 'n situasie waar jy maar onbepaald as lidmaat van die kerk gereken word bloot op grond van jou ouers se lidmaatskap van die kerk en geloof, onhoudbaar is. Dit lyk eerder of so 'n ongekwalifiseerde handhawing van die derde kategorie van lidmaatskap deel is van 'n tipe corpus christianum.

Ander artikels van die kerkwet help ook nie om die posisie van die kind op te klaar of duidelik te omskryf nie. Artikel 16 van die kerkwet sê slegs dat die kind gedoop word op grond van die verbond, sonder om lidmaatskap enigsinds te vermeld. Artikel 17 handel oor die kategese, en stel dat die kategese moet lei tot 'n openbare belydenis van geloof, die gebruik van die sakramente en verantwoordelike lidmaatskap van die kerk. Hierdie artikel skep die indruk dat lidmaatskap van die kerk eers ' $n$ werklikheid word na belydenis van geloof. Hierdie indruk word bevestig deur artikel 18 van die kerkwet waar gepraat word oor die openbare belydenis van geloof: Hier word uitdruklik gesê dat jy in die gemeente opgeneem word met die aflê van geloofsbelydenis, en dan, op grond van die lidmaatskap van die kerk, nagmaal kan gebruik.

Daar is dus teëspraak tussen artikels 3 en 18 van die kerkwet, aangesien artikel 3 sê dat jy reeds by jou doop, en selfs as ongedoopte, lidmaat van die kerk is en artikel $18 \mathrm{sê}$ jy word in die gemeenskap van die gelowiges opgeneem met aflegging van geloofsbelydenis. Is daar 'n verskil tussen die kerk en die gemeenskap van gelowiges?

Om die saak verder te kompliseer bepaal die kerkwet dat die dooplidmaat onder die opsig van die kerkraad staan. Daar word van die dooplidmaat verantwoordelike lidmaatskap verwag (vgl artikel 17). Daar word gesê dat die dooplidmaat verantwoordelik is om kategese by te woon, Bybel te lees en te bid, die erediens by te woon en 'n Christelike lewe te lei. 
Uit bogenoemde voorbeelde is dit duidelik dat daar in die kerkwet van die NHKA nie op 'n eenvormige wyse oor lidmaatskap gepraat word nie, en dat daar selfs 'n mate van spraakverwarring is. Daardeur kom die posisie van die kind in die kerk in die gedrang. Dit is noodsaaklik dat daar oor hierdie sake helderheid moet kom.

\subsection{Kerkregtelike agtergrond van die bepalings ten opsigte van lidmaatskap}

Die onderskeiding tussen gedoopte, belydende en nie-gedoopte lidmate het sy wortels in die vroegste kerkordes, maar nie by Calvyn nie. Die Ordonannances Ecclesiastiques wat deur Calvyn opgestel is, is op 20 November 1541 met trompetgeskal en klokgelui in Geneve aangekondig (Pont 1981:21). Volgens hierdie kerkorde was ouers verplig om hulle kinders te doop. Daar is streng opgetree teen mense soos die Anabaptiste wat die kinderdoop bestry het. Michael Servet, wat bo en behalwe sy anti-trinitariese leer ook ten opsigte van die doop met die vadere van die kerkhervorming verskil het, het met sy lewe betaal vir sy afwykende leer. Die feit dat hy 'n beroemde geleerde was wat bloedsomloop ontdek en beskryf het, het hom nie van die brandstapel gered nie. Volgens die Geneefse kerkorde moes al die kinders gedoop word, moes almal katkiseer en uiteindelik moes almal belydenis van geloof aflè. Wat egter opvallend is, is dat die Geneefse kerkorde nerens sê dat jy eers in die gemeenskap van die gelowiges opgeneem word met die aflê van die openbare belydenis van geloof nie. Inteendeel - dit word duidelik gestel dat lidmaatskap van die kerk volg op die doop. Dit word ook bevestig deur Calvyn se uiteensetting van die doop in sy Institutio. In Inst.4.15.1 (Sizoo se vertaling) se Calvyn: 'De doop is een teken der inwijding, waardoor wij tot de gemeenschap der kerk worden aangenomen, opdat wij, in Christus ingeplant, onder Gods kinderen word gerekend'. Die doop is dus vir Calvyn 'n inisiasie in die kerk. Hierin sluit Calvyn baie nou by Luther aan (Wendel 1987:319). Die gebruik was dan ook dat die kinders so vroeg as die agtste dag na geboorte gedoop is, dikwels sonder dat die moeder teenwoordig was.

Die geloofsbelydenis het dan volgens die Geneefse kerkorde die funksie om aan die katkisant die geleentheid te bied om in die openbaar te kenne te gee dat hy instem met dit wat hy geleer het uit die Woord van God, dat hy instem met die leer van die kerk en genoegsame kennis en onderskeidingsvermoë het om nagmaal te kan gebruik. Hier is dus geen drieledige onderskeid ten opsigte van lidmaatskap nie. Die kind word lidmaat van die kerk by sy doop, en die geloofsbelydenis dien geen funksie ten opsigte van lidmaatskap nie. Teenoor Calvyn het Bucer in sy kerkorde die geloofsbelydenis omskryf as 'n opname in die gemeenskap van die gelowiges (Pont 1991:440). Bucer se kerkordelike invloed is in die opsig duidelik te 
sien in die latere kerkordes van die reformasie. Die latere kerkordes het Bucer se siening dat lidmaatskap op die geloofsbelydenis volg, behou. So vind ons bv. in die kerkorde wat die Konvent van Wezel in 1568 opgestel het, dat daar in art. 48 gesê word: En voorwaar, alle die voor ledematen in de kerk gehouden willen worden, zullen zo haast de jaren der kinderen dit toelaten, zich laten catechiseeren... (Pont 1981:82; my beklemtoning).

Hierdie gedagte dat jy eers lidmaat van die kerk word na katkisasie en die aflê van geloofsbelydenis word hierna in al die Nederlandse kerkordes voortgesit. Die nasionale sinode wat te Dordrecht in 1587 vergader het, het hierdie standpunt in artikel 64 verder bevestig (Pont 1981:138). In hierdie kerkorde word baie duidelik uiteengesit dat die kind op grond van die verbond gedoop word, volwassenes word gedoop op grond van hul geloofsbelydenis. In die geval van volwassenes volg lidmaatskap direk op die doop, maar in die geval van kinders bly lidmaatskap uit tot en met die aflè van die geloofsbelydenis. Daar word dus onderskeid getref tussen die kind-gedoopte en volwasse gedoopte. Die volwasse gedoopte is 'ten volle' lidmaat van die kerk en kan dan ook nagmaal gebruik. Die kind gedoopte is hoogstens 'voorlopig' lidmaat van die kerk. Dit is hierdie gedagte wat deurloop tot in ons eie kerkwet. Met die opstel van die huidige kerkwet is daar sekerlik nie doelbewus gekies vir Bucer se standpunt teenoor die van Calvyn nie. Dit lyk eerder of daar onnadenkend die kerklike praktyk van die eeue voortgesit is.

\subsection{Genadeverbond}

In die nagaan van die kerkordes staan een begrip sentraal ten opsigte van lidmaatskap, en dit is die genadeverbond. Die kerkwet gee daaraan uitdrukking in artikel 2: 'Ter wille van die goeie orde word almal wat deur die genadeverbond tot die kerk behoort, in gemeentes byeengebring' (my beklemtoning). Die doop funksioneer dan ook as die uiterlike teken van die genadeverbond (Van Wyk 1991:247). Met hierdie verbondsmatige kerkbegrip is daar nie sprake van dat dat jy vrywillig uit eie vrye keuse lidmaat van die kerk word nie. Dit is teologies inkonsekwent om aan die een kant vas te hou aan die genadeverbond as grond van lidmaatskap van die kerk, en aan die ander kant te sê dat ' $n$ kind met sy belydenis van geloof moet aandui of hy 'lidmaat van die kerk wil word'. Die implikasie daarvan is dat die kerkwet botsende begrondings van hidmaatskap (vrye kerk teenoor verbondskerk) akkomodeer. Die kind word op grond van die genadeverbond in die kerk 'ingebore', omdat hy deel is van 'n gelowige huisgesin, wat deel is van die gemeente as volk van God. As teken dat die kind deur die genadeverbond in die liggaam van Christus ingelyf word, word hy gedoop. Doop, kategese, geloofsbelydenis en die uiteindelike gebruik van die nagmaal berus alles op die genadeverbond (Pont 1991:441). 
Die verbondsteologie staan vandag in die spervuur (vgl Venter 1984:55-66). Dit is nie die bedoeling om die problematiek ten opsigte van die verbondsteologie hier breedvoerig te behandel nie. Venter toon aan dat vandag nie meer van die verbondsteologie gepraat kan word nie, maar eerder van 'n verskeidenheid van verbondsteologië. Tog bly die verbond ' $n$ kernaspek van die verhouding tussen God en mens. Die verbond realiseer wel op verskillende maniere, maar is steeds 'n legitieme begronding van die doop en van lidmaatskap. Dit bly steeds relevant en legitiem om te sê dat die doop iets van die verbond tussen God en mens realiseer (Venter 1984:66). Die verbond vorm dus ten regte die basis van die kerk se denke oor lidmaatskap van die kerk, en tog word dit nie konsekwent deurgevoer nie.

\section{DOOP}

Uit alles wat hierbo gesê is, word dit duidelik dat die waarde van die doop nie onderskat of ondermyn mag word nie. Die kind word op grond van die genadeverbond gedoop, word so in die verbondsvolk, die kerk, ingelyf en is dus lidmaat van die kerk. Dit is so dat die verbond primêr 'n Ou Testamentiese perspektief is, maar ook die Nuwe Testament verbind die doop aan die eenword met die liggaam van Christus. Romeine 6:1-11 sê dat die dopeling een word met Christus in sy dood en opstanding. Daar vind 'n inlywing in Christus plaas - en dit het die implikasie van lidmaatskap van die kerk, want die kerk is tog allereers organies die liggaam van Christus en nie instituut nie. Daarom sê die doopformulier dat wanneer ons in die Naam van die Heilige Gees gedoop word $\mathrm{Hy}$ in ons wil woon en ons tot lede van Christus wil maak (Diensboek NHKA 1987:56). Uit die konteks van die formulier word dit duidelik dat die inlywing in die kerk nie eers plaasvind wanneer ons belydenis van geloof aflê nie, maar de facto by die doop plaasvind. Die formulier weerspieël die Calvinistiese gedagte dat die doop ' $n$ inisiasie in die kerk is, waarna daar in afdeling 2.2 verwys is.

Op grond van Skriftuurlike gegewens vanuit die Ou- en die Nuwe Testament moet 'n mens saamstem met Calvyn dat die kind reeds by sy doop lidmaat van die kerk is. ' $n$ Drievoudige onderskeiding van lidmaatskap is problematies as dit so verstaan word dat jy eers 'volle' lidmaat van die kerk word as jy belydenis van geloof aflê. Die kind word met sy doop lidmaat van die kerk: deur dít te verwaaarloos in ons teologiese nadenke en in die kerkwet, verduister ons die heilsbetekenis van die doop vir die gelowige (kind). Ook Ridderbos stel in sy interpretasie van die doop in die Pauliniese geskrifte dat die doop by Paulus nie net gaan om ' $n$ afwassing van die sonde nie, maar ook as 'n inlywing in die kerk van Christus (Ridderbos 1973:451).

Die doop is onder andere 'n sigbare wyse van toetrede tot die kerk. Die kind wat op grond van die uitverkiesing en genadeverbond gedoop is, is deel van die liggaam van Christus, en dus lidmaat van die kerk. 


\section{NAGMAAL}

Die vraag wat 'n mens nou kan vra, is of die gedoopte as lidmaat van die kerk nie dan ook nagmaal moet gebruik nie. Hoewel die nagmaal ook verbondsmaal en gemeenskapsmaal is (Dreyer 1986:145 en 146), wat daarop sou kon dui dat die gedoopte as deel van die verbond en as deel van die gemeenskap van die gelowiges nagmaal moet gebruik, is daar tog faktore wat die nagmaal anders laat funksioneer as die doop. Hierdie andersheid het daarmee te make dat die Skrif (1 Kor 11:27-31) uitdruklik van die nagmaalsgebruiker 'n bepaalde onderskeidingsvermoë vra: Die nagmaalsgebruiker moet homself krities kan ondersoek of hy besef dat die brood en wyn op die liggaam en bloed van Christus dui. Sonder hierdie kritiese onderskeidingsvermoë eet en drink hy 'n oordeel oor homself. Die kerk het altyd redelikerwys hierdie kritiese onderskeidingsvermoë alleen by lidmate van die kerk verwag wat gekatkiseer het, genoegsame kennis verwerf het en daarom ook belydenis van geloof afgelê het. Voor die afle van die openbare belydenis van geloof is die katkisant dan ook ondervra om vas te stel of hy sodanige insig in die evangelie van Jesus Christus het, dat hy met vrymoedigheid nagmaal kan gebruik. Die gebruik van nagmaal is dus nie primer gebind aan 'lidmaatword' nie, maar aan die lidmaat se kennis en onderskeidingsvermoë.

In so 'n benadering van die nagmaal gaan dit nie om inkonsekwensie in teologiese denke, diskriminasie teen die kind of minagting van die dooplidmaat nie. Die kind as gedoopte is en bly lidmaat van die kerk in die volle sin van die woord, maar vanweë natuurlike beperkings ten opsigte van kennis en insig is dit nodig dat hy eers katkiseer voordat hy nagmaal kan gebruik. So beskerm die kerk die kind daarvan om 'n oordeel oor homself te eet en te drink. Hiermee saam moet 'n mens dan ook sê dat ander lidmate, soos verstandelik gestremdes en seniele bejaardes, se deelname aan die nagmaal problematies is omdat hulle, soos kinders, 'n gebrek aan onderskeidingsvermoë het. $\mathrm{Na}$ alles is die nagmaal nie 'n magiese middel wat aan ons die ewige lewe toedeel nie - die doel van die nagmaal is om ons geloof te versterk wanneer ons met insig en onderskeiding daaraan deelneem. Calvyn het die saak baie duidelik uiteengesit in sy polemiek teen die Roomse mis en die gratia infusis wat daarmee verkondig word.

Nagmaalgebruik volg op die belydenis van geloof, nie omdat jy dan lidmaat van die kerk word en dus die voorreg verwerf om nagmaal te gebruik nie, soos wat in artikel 18 van ons kerkwet gesê word nie, maar omdat die kategese kennis en insig van die evangelie meebring. Van daardie kennis en insig word met die afle van die geloofsbelydenis getuig. Met daardie kennis en insig kan jy sinvol nagmaal gebruik sonder om 'n oordeel oor jouself te eet en drink. Indien die kerk kinders vroeër wil laat nagmaal gebruik, moet die kategese-program vroeër afgesluit word, met dien 
verstande dat die kind die nodige insig het om nagmaal te gebruik. In die tyd van Calvyn het kinders reeds op twaalfjaar belydenis van geloof afgele en ook nagmaal gebruik.

\section{OPSIG EN TUG}

Die kind as gedoopte lidmaat van die kerk staan ten volle onder die opsig van die kerkraad. Bepaling 101.1 van die kerkwet bepaal 'die kerkraad hou opsig oor dooplidmate en ongedooptes deur toe te sien dat hulle gereeld kategetiese onderrig ontvang, gereeld Bybel lees en bid, eredienste getrou bywoon en 'n Christelike lewe lei'. Daar word dus in wese dieselfde van 'n kind in die kerk verwag as van 'n volwassene, naamlik om as Christen gelowig en gehoorsaam aan God te lewe. Die bedoeling van die kerkwet is ook dat dit nie net die ouer se verantwoordelikheid is om sy kind Christelik groot te maak nie, maar dat die kind ook sy eie verantwoordelikheid dra. Daarom kan die kind dan ook getug word, veral deur bestraffing.

Solank as wat die kind nog nie belydenis van geloof afgelè het en nagmaal gebruik nie, is die sensuur of weerhouding van die sakramente nie prakties moontlik nie. In die praktyk vind daar tog iets van die sensuur en ban plaas: As die kind 'n gedoopte lidmaat van die kerk is, soos reeds aangedui, en die kerkraad sou byvoorbeeld op grond van gebrekkige kennis, gesindheid of lewenswyse weier dat 'n kind belydenis van geloof afle, en daardie kind word nie verder bearbei nie, kom die kind vir alle praktiese doeleindes buite die gemeenskap van die gelowiges te staan. In ieder geval word hy weerhou om nagmaal te gebruik, en dit is niks anders as sensuur nie. Ook ten opsigte van dié saak lyk dit of ons met groot huiwering 'n volwassene uit die kerk ban, maar dit geredelik doen met kinders omdat ons dalk van opinie is dat hulle hoogstens voorlopig lidmaat van die kerk is. Dit is 'n growwe aantasting van die betekenis van die doop as 'n inlywing in die liggaam van Christus.

\section{GEVOLGTREKKINGS}

- Die kind word met sy doop lidmaat van die kerk, en nie wanneer hy belydenis van geloof aflê nie;

- as lidmaat van die kerk is die kind verantwoordelik om Christelik te lewe;

* die kind kan getug word;

* die kind gebruik eers nagmaal na deeglike kategetiese onderrig;

- die kind behoort by verhuising ook 'n bewys van lidmaatskap te ontvang; en

* die kerk moet ophou om in sy prediking en in die kerkwet die waarde van die doop te ondermyn, deur te maak of jy eers lidmaat van Christus word as jy belydenis van geloof aflè. 


\section{Literatuurverwysings}

Calvyn, J 1559. Institusie III/4. Naamloze Vennootschap W D Meinema: Delft. Dreyer, P S 1985. Geboorte, huwelik, dood. Kital: Pretoria.

Dreyer, W A 1986. Sakrament-Doop- Nagmaal, in Beukes, M J du P (red), Glo die Woord, 130-149. Kital: Pretoria.

Nederduitsch Hervormde Kerk van Afrika 1989. Kerkwet. Pretoria: Kital.

Lombard, I M 1983. Problematiek van die kindernagmaal. Ongepubliseerde BDskripsie, Universiteit van Pretoria.

Pieterse, H J C 1979. Skrifverstaan en prediking. NGK Boekhandel: Pretoria.

Pont, A D 1981. Historiese agtergronde van ons kerklike reg. Deel 1. HAUM: Pretoria.

- 1991a. Historiese agtergronde van ons kerklike reg. Deel 2. Kital: Pretoria.

— 1991b. Kategese, kategismusse en die belydenis van geloof. HTS 47/2, 431441.

Ridderbos, H 1973. Paulus: Ontwerp van zijn teologie. J H Kok BV: Kampen. Van Wyk, B J 1991. Die presbiteraal-sinodale kerkbegrip. Kital: Pretoria. Venter, P M 1984. Verbondsteologie: 'n Tendensstudie. HTS 40/4, 55-68.

Wendel, F 1978. Calvin. Collins: London. 